\title{
The Effects of Naltrexone on Subjective Response to Methamphetamine in a Clinical Sample: a Double-Blind, Placebo-Controlled Laboratory Study
}

\author{
Lara A Ray ${ }^{*, 1,2}$, Spencer Bujarski', Kelly E Courtney', Nathasha R Moallem', Katy Lunny', Daniel Roche', \\ Adam M Leventhal ${ }^{3}$, Steve Shoptaw ${ }^{2,4}$, Keith Heinzerling ${ }^{2,4}$, Edythe D London ${ }^{2,5}$ and Karen Miotto ${ }^{2}$ \\ 'Department of Psychology, University of California, Los Angeles, Los Angeles, CA, USA; '2Department of Psychiatry and Biobehavioral Sciences, \\ University of California, Los Angeles, Los Angeles, CA, USA; ${ }^{3}$ Departments of Preventive Medicine and Psychology, University of Southern Califormia \\ Keck School of Medicine, Los Angeles, CA, USA; ${ }^{4}$ Department of Family Medicine, University of California, Los Angeles, Los Angeles, CA, USA; \\ ${ }^{5}$ Department of Molecular and Medical Pharmacology, University of California, Los Angeles, Los Angeles, CA, USA
}

\begin{abstract}
Methamphetamine (MA) use disorder is a serious psychiatric condition for which there are no FDA-approved medications. Naltrexone (NTX) is an opioid receptor antagonist with demonstrated efficacy, albeit moderate, for the treatment of alcoholism and opioid dependence. Preclinical and clinical studies suggest that NTX may be useful for the treatment of MA use disorder. To inform treatment development, we conducted a double-blind, randomized, crossover, placebo-controlled human laboratory study of NTX. Non-treatmentseeking individuals meeting DSM-IV criteria for MA abuse or dependence $(n=30)$ completed two separate 5-day inpatient stays. During each admission, participants completed testing sessions comprised of MA cue-reactivity and intravenous MA administration (30 mg) after receiving oral NTX $(50 \mathrm{mg})$ or placebo for 4 days. This study tested the hypotheses that NTX would (a) attenuate cue-induced MA craving, and (b) reduce subjective responses to MA administration. Results largely supported the study hypotheses such that (a) NTX significantly blunted cue-induced craving for MA and (b) attenuated several of the hedonic subjective effects of MA, including craving, during controlled MA administration and as compared with placebo. NTX decreased overall subjective ratings of 'crave drug,' 'stimulated,' and 'would like drug access,' decreased the the post-MA administration timecourse of 'anxious' and increased ratings of 'bad drug effects,' as compared with placebo. These findings support a potential mechanism of action by showing that NTX reduced cue-induced craving and subjective responses to MA. This is consistent with positive treatment studies of NTX for amphetamine dependence, as well as ongoing clinical trials for MA.

Neuropsychopharmacology (20I5) 40, 2347-2356; doi: I0.I038/npp.20I5.83; published online I5 April 20 I5
\end{abstract}

\section{INTRODUCTION}

Recent estimates suggest that over 12 million people in the United States, ages 12 years and older (4.7\% of total responders) have used methamphetamine (MA) in their lifetimes, with over 379,000 of those individuals meeting DSM-IV criteria for MA dependence (Substance Abuse and Mental Health Services Administration (SAMHSA), 2013). Efficacious pharmacotherapies for MA use disorder remain elusive despite extensive research on the neurobiology of the effects of amphetamines (Brensilver et al, 2013; Elkashef et al, 2008). Naltrexone (NTX) is an opioid receptor antagonist with empirically supported efficacy and FDA approval for the treatment of alcoholism (Anton et al, 2006;

\footnotetext{
*Correspondence: Dr LA Ray, Department of Psychology, University of California, Los Angeles, I 285 Franz Hall, PO Box 95 I 563, Los Angeles, CA 90095- I563, USA, Tel: + I 310794 5383, Fax: + I 3102065895 , E-mail: lararay@psych.ucla.edu.

Received 8 August 2014; revised 20 February 2015; accepted 23 February 2015; accepted article preview online 24 March 2015
}

O'Malley et al, 1992; Volpicelli et al, 1992) and opioid dependence (Cornish et al, 1997). Preclinical models suggest that NTX may also affect MA use, as NTX attenuated MA-induced sensitization (Chiu et al, 2005), amphetamine drug-seeking reinstatement (Haggkvist et al, 2008), and cue-induced MA seeking in rodents (Anggadiredja et al, 2004). In particular, preclinical studies suggested that $\mu$-opioid (Chiu et al, 2006) and $\delta$-opioid (Suzuki et al, 1997) receptors may underlie MA-induced behavioral sensitization, analogous to compulsive drug-seeking behavior in humans (ie, drug craving; Itzhak and Ali, 2002), through its modulatory actions of the mesolimbic dopamine system (Ford et al, 2006). Preclinical studies have observed NTXrelated decreases in d-amphetamine and alcohol selfadministration in adult rhesus monkeys (Jimenez-Gomez et al, 2011), and attenuated amphetamine-induced reinstatement with no effect on food-taking behavior in rats (Haggkvist et al, 2009).

A few clinical studies have tested NTX in amphetamine users. Notably, a placebo-controlled clinical trial found that 
NTX (50 mg) significantly increased amphetamine abstinence compared with placebo, as measured by negative urine samples, over the course of 12 weeks of treatment (JayaramLindstrom et al, 2008a). A related placebo-controlled human laboratory study found that NTX $(50 \mathrm{mg})$ blunted craving and subjective responses during a dexamphetamine $(30 \mathrm{mg}$ oral) challenge in a sample of amphetamine-dependent subjects (Jayaram-Lindstrom et al, 2008b), as well as in healthy controls (Jayaram-Lindstrom et al, 2004). On balance, these preclinical and clinical studies suggest that modulation of the endogenous opioid system via NTX may be useful for the treatment of MA use disorder.

In recent years, there has been renewed interest in the application of NTX for drug dependence. A clinical trial of a NTX depot implant demonstrated significant benefit over placebo on measures of treatment retention, drug-free urines, and global assessments of functioning in a hard-totreat sample of heroin and amphetamine polydrugdependent individuals (Tiihonen et al, 2012). Further, a recent behavioral pharmacology study found that acute oral NTX significantly reduced craving during cocaine administration in a sample of non-treatment-seeking cocaine users $(n=12)$ (Comer et al, 2013). However, in the aforementioned study, NTX did not alter the cardiovascular or subjective effects of smoked cocaine $(0,12.5,25$, and $50 \mathrm{mg}$ ), and as oral amphetamine $(0,10$, and $20 \mathrm{mg})$ produced no discernable subjective effects, NTX effects on subjective response to amphetamine could not be assessed in this sample. If NTX were to blunt subjective response to intravenous (IV) MA, that may be indicative of its ability to also blunt less reinforcing routes of MA administration. In summary, these recent studies suggest that NTX may reduce drug use (heroin and amphetamines) in a clinical sample and attenuate cocaine craving in the lab. On the basis of these results along with the preclinical literature, testing NTX for MA use disorder represents a promising avenue towards advancing medication development.

This study uses a human behavioral pharmacology approach to elucidate the biobehavioral mechanisms of NTX for MA dependence by focusing on the effects of NTX on cue-induced craving for MA and on subjective responses to MA in the laboratory. In this double-blind, randomized, crossover, placebo-controlled trial, non-treatment-seeking individuals meeting DSM-IV criteria for MA abuse or dependence $(n=30)$ completed two separate 5-day inpatient stays. During each admission, participants completed testing sessions comprised of MA cue-reactivity and MA administration (30 mg IV) after receiving NTX (50 mg) or placebo for 4 days. This study tested the hypotheses that NTX would (a) attenuate cue-induced MA craving, and (b) attenuate subjective responses to MA administration.

\section{PATIENTS AND METHODS}

\section{Participants}

A community-based, non-treatment-seeking sample of MA users was recruited via online and print advertisements in the Los Angeles area. The study protocol and all procedures were approved by the Institutional Review Board of the University of California, Los Angeles. Inclusion criteria were to: (a) meet current DSM-IV criteria for MA abuse or dependence; (b) be fluent in English; (c) be between 18 and 50 years of age; (d) produce MA-positive urine prior to study entry; and (e) agree to abstain from MA during the study, as evidenced by a MA-negative urine upon each inpatient admission and every morning during their stay. Exclusion criteria were to: (a) be currently in treatment for MA use, have a history of treatment in the 30 days before enrollment, or be currently seeking treatment for MA use; (b) receive a DSM-IV diagnosis of current (last 12 months) drug dependence, other than MA, lifetime schizophrenia, bipolar disorder, or any psychotic disorder, or current major depressive disorder (MDD) with suicidal ideation; (d) report current use of psychoactive drugs, other than marijuana and MA, verified by a toxicology screen; (e) have significant medical problems, as indicated by physical examination or laboratory tests (ie, a blood chemistry panel and liver profile); (f) report currently taking any medications that could interact adversely with NTX; (g) testing positive for pregnancy, are currently nursing, or refusing to use reliable methods of birth control, (h) report intranasal as the only route of MA administration, and (i) cardiovascular abnormalities in electrocardiogram (EKG) or vital signs (eg, $\mathrm{HR}<50$ or $>90$; $\mathrm{SBP}<105$ or $>140, \mathrm{DBP}<45$ or $>90$ ), as determined during the physical exam.

A total of 126 individuals ( $74 \%$ male) completed an initial in-person screening session, and 46 individuals completed a secondary medical screening with the study physician. Study attrition from screening to enrollment was due to: (a) participant dropout $(n=32)$, (b) inability to produce a positive MA urine to verify MA use history $(n=18)$, (c) positive urine test for other exclusionary substances $(n=7)$ and (d) failing to meet eligibility criteria based on the Structured Clinical Interview for DSM-IV (SCID; either not meeting MA abuse/dependence criteria or meeting criteria for other exclusionary psychological conditions; $n=14$ ). Thirty-two individuals (75\% male, mean age $=36.47$ (SD $=$ 8.68)) completed at least one experimental session, 30 of whom $(73.3 \%$ male, mean age $=36.93(\mathrm{SD}=8.77))$ completed both experimental sessions, one while at the target dose of NTX and the other on matched placebo, and were included in the final analyses.

\section{Screening Procedures}

Interested individuals called the laboratory and completed a telephone-screening interview. Eligible callers were invited to the laboratory, and after receiving a full explanation of study procedures and providing written, informed consent, participants completed the in-person screening visit. At the beginning of the screening visit, participants were required to have a breath alcohol concentration of $0.00 \mathrm{~g} / \mathrm{dl}$, produce a positive MA test result on a urine toxicology screen, and have negative test results for all other drugs (excluding marijuana). Participants then completed questionnaires on demographics, drug-use history, and psychological functioning. The following interviews were administered by trained masters-level clinicians: (a) the 30-day Timeline FollowBack to capture daily MA use over the 30 days prior to the visit (Sobell et al, 1988); and (b) the SCID (First, 2005) to assess criteria for MA dependence and abuse, and to screen for exclusionary psychiatric diagnoses. Regarding MDD, a total of four participants reported depressed mood in the 
2 weeks prior to the assessment (ie, met screening item of the SCID MDD module), yet the complete assessment of depressive symptoms revealed none of the four participants met criteria for a current major depressive episode.

Participants deemed eligible following the in-person screening were invited to return to the laboratory to complete a physical exam with the study physician (KM). Participants were required to provide a negative urine toxicology screen for all drugs (including MA, excluding marijuana) at the time of the physical exam, which consisted of clinical laboratory testing (ie, a blood chemistry panel and liver profile), and an EKG.

\section{Medication Administration and Inpatient Procedures}

Individuals who passed the physical exam were then admitted to the UCLA Clinical and Translational Research Center (CTRC) inpatient unit on the same day, at which time they were randomized to take the first study medication (NTX or matched placebo). Participants took the study medication under staff supervision for 4 days and completed the first experimental session on medication day 4, which consisted of a cue-reactivity paradigm and an IV MA administration. The last dose of NTX, or placebo, was administered $2 \mathrm{~h}$ prior to the MA infusion. Participants were discharged from the unit on day 5, and following a 7-14-day washout period were re-admitted to the hospital for their second inpatient stay at which time they received the second study medication (NTX or placebo), in counterbalanced, randomized, and double-blind fashion. NTX was titrated, to minimize adverse events (AEs), from $25 \mathrm{mg}$ on day one to $50 \mathrm{mg}$ doses on days two through four. Side effects were monitored throughout each inpatient stay using the Systematic Assessment for Treatment Emergent Effects (SAFTEE) (Levine and Schooler, 1986). Following completion of the study and prior to discharge on day 5, participants completed a motivational interview session targeting MA use reduction and promoting treatment seeking. The intervention was delivered by a Master's level clinician under the supervision of a licensed psychologist (LAR). Participants received $\$ 40$ for completing the in-person screening visit and were compensated $\$ 40$ per inpatient day ( $\$ 400$ total) and $\$ 50$ for each of the two experimental sessions. Participants who completed all parts of the study received a $\$ 100$ bonus.

\section{Cue-Reactivity Paradigm and Measures}

On day 4 of each admission, participants completed a guided cue-exposure protocol (Monti et al, 1987) modified for relevance to MA. The cue-exposure protocol included the presentation of two audiotaped scripts (MA and control), each $\sim 5 \mathrm{~min}$ in length, delivered in a non-counterbalanced fashion (neutral first) to avoid potential carryover effects. The scripts instructed the participant to recall sensory and emotional memories related to their use of MA (or water). At various times during the exposures, the participant was instructed to handle physical cues (eg, glass MA pipe or glass of water) to increase the potential for cue-related reactivity. Previous work has shown MA paraphernalia exposure to be similar to video and pictorial cue exposure in terms of eliciting significant cue-induced MA craving
(Tolliver et al, 2010). After each standardized exposure, participants completed the MA urge questionnaire (MAUQ), which was adapted from previously published and validated studies of craving assessment (Bohn et al, 1995; MacKillop, 2006). The MAUQ, an eight-item questionnaire, captures craving by having participants indicate how much they agree or disagree with a series of statements regarding MA. Examples of these statements include, 'All I want to do now is use methamphetamine,' 'It would be difficult to turn down methamphetamine at this minute,' and 'I want to use methamphetamine so bad I can almost feel it.' An average of the items was computed, and internal reliability for this measure was very high at each assessment (Cronbach's $\alpha \geqslant 0.95$; variance explained by a one-factor solution $\geqslant 85 \%$ ). Measures of heart rate and blood pressure were recorded before and after cue administration in each condition.

\section{MA Administration Procedures and Measures}

Approximately $2 \mathrm{~h}$ after the cue-reactivity paradigm, participants completed a MA challenge, consisting of two $15 \mathrm{mg}$ IV MA infusions administered over $2 \mathrm{~min}$, separated by $30 \mathrm{~min}$ for safety monitoring, for a total dose of $30 \mathrm{mg}$. The IV administration method was selected to provide optimal control over MA dosing, and previous research demonstrated a similar pattern of pharmacokinetic and subjective response to MA when comparing IV and smoking routes of administration (Cook et al, 1993). Assessment of subjective responses began immediately following the second dose administration. Continuous cardiac telemetry, serial EKG, and vital signs were monitored during and after the infusions. Cardiac functioning was monitored using a GE Dash4000 EKG monitor, and the MA was administered using a Baxter AS50 syringe pump. The study physician (KM) was present for each MA infusion along with a registered nurse and study staff. Measures of subjective responses to MA (ie, the drug effects questionnaire; DEQ), MA craving (ie, MAUQ), and cardiovascular function (ie, heart rate and blood pressure) were collected prior to MA administration (ie, baseline) and then again at 5, 10, 15, 20, $30,60,90$, and $120 \mathrm{~min}$ following the second 15-mg MA administration. The DEQ is an 11-item questionnaire that captures subjective effects (Morean et al, 2013) comprised of questions such as, 'How much do you feel any drug effects?', 'How bad are the drug effects you are feeling right now?' in contrast to 'How good are the drug effects you are feeling right now?,' 'How much would you like to access the drug right now?', and 'How much do you like the effects you are feeling now?' Participants are asked to rate their current feelings on a Likert scale ranging from 0 (none at all) to 10 (a lot). Participants were asked in an open-ended fashion to report on any AEs experienced during the MA infusion. AEs were assessed after the MA infusion session on day 4 and before discharge on day 5 .

\section{Medication and MA}

Naltrexone. NTX was purchased from and compounded by Bayview Pharmacy (Saunderstown, RI) into blister packs containing the 25- and 50-mg doses. These doses were administered orally in one capsule each day. The matched placebo was administered in one capsule each day. 
Participants took the study medication daily under the observation of CTRC research nursing staff. Medication order was randomized and counterbalanced.

Methamphetamine Hydrochloride ( $\mathrm{HCl})$. MA $\mathrm{HCl}$ was provided by a NIDA contractor. The UCLA Investigational Drug Pharmacy prepared two $15-\mathrm{mg}(5 \mathrm{ml})$ infusions in $0.9 \%$ sodium chloride solution for each MA administration session. The dose selected and administration procedures were consistent with previous behavioral pharmacology studies (Newton et al, 2008; Newton et al, 2006), having demonstrated safety and efficacy in producing elevations in subjective effects.

\section{Statistical Analyses}

Repeated measures analyses of variance (ANOVA) were used to analyze the effects of NTX on cue-induced craving and subjective response to the MA challenge. For each test, we were interested in the main effect of medication (NTX $v s$ PLAC), the main effect of trial (ie, pre-post cue exposure, or time after acute MA), and the medication $\times$ trial interaction. For the analyses of subjective effects during the MA administration, we tested medication condition differences on change from baseline across the trial, namely 5, 10, 15, 20, 30, 60, 90, and $120 \mathrm{~min}$ following MA administration. Notably, there were no significant baseline differences on the subjective response measures of interest across the two medication conditions, $p$ values $\geqslant 0.09$. For variables showing a significant medication $\times$ trial effect, post hoc tests were conducted to determine at which time points in the trial the medication groups were significantly different. Post hoc analyses assessing medication differences at each post-MA administration time point were conducted using repeated measures ANOVA with medication as a within-subject factor. Relevant covariates were considered (eg, sex, age) but ultimately not found useful, largely because in the crossover design participants serve as their own controls. An alpha threshold of 0.05 was set for all statistical analyses, including post hoc comparisons.

\section{RESULTS}

\section{Sample Characteristics}

Thirty participants who completed the entire study were included in the statistical analyses reported herein. Sample characteristics are reported in Table 1, including details on MA use quantity and frequency. Twenty-six participants met DSM-IV diagnostic criteria for MA dependence, whereas four met for MA abuse without dependence. When converting to the DSM-V criteria (craving symptom not assessed/included), all participants were found to meet criteria for current (ie, past month) MA use disorder (19\% mild, 25\% moderate, and 56\% severe). All subjects reported experience smoking MA because intranasal-only users were excluded for safety reasons.

\section{Cue Reactivity}

Craving. Analyses revealed a significant medication $\times$ trial effect on cue-induced craving for $\mathrm{MA},(\mathrm{F}(1,29)=4.32$, $p<0.05)$, such that NTX attenuated cue-induced craving
Table I Sample Demographics

\begin{tabular}{|c|c|c|}
\hline Variable & $\begin{array}{l}\text { Frequency or } \\
\text { mean (SD) }\end{array}$ & Range \\
\hline Age & $36.93(8.78)$ & $23-50$ \\
\hline Sex-male/female & $22 / 8$ & - \\
\hline \multicolumn{3}{|l|}{ Ethnicity } \\
\hline Latino & 7 & - \\
\hline Caucasian & 11 & \\
\hline African American & 4 & \\
\hline Asian & 2 & \\
\hline Mixed & 6 & \\
\hline \multicolumn{3}{|l|}{ Primary route of MA administration } \\
\hline Smoking & 28 & - \\
\hline Snorting & 1 & \\
\hline Injection & 1 & \\
\hline Age of first MA use & $24(9.83)$ & $13-47$ \\
\hline Years of MA use & $12.48(8.46)$ & $<1-32$ \\
\hline $\begin{array}{l}\text { DSM-IV MA abuse/dependence } \\
\text { symptom count }\end{array}$ & $6.00(2.26)$ & $2-11$ \\
\hline Number of MA use days (past 30 days) & $21.26(8.15)$ & $9-30$ \\
\hline Education (years) & $12.19(3.41)$ & $4-21$ \\
\hline \multicolumn{3}{|l|}{ Current drug use } \\
\hline Alcohol & 21 & - \\
\hline Marijuana & 9 & \\
\hline Cocaine/crack & 0 & \\
\hline Ecstasy & 0 & \\
\hline Heroin & 0 & \\
\hline \multicolumn{3}{|l|}{ Cigarettes per day (past week) } \\
\hline 0 & II & - \\
\hline $1 \leqslant 10$ & 9 & \\
\hline$>10$ & 10 & \\
\hline $\begin{array}{l}\text { Number of alcohol-drinking days (past } \\
30 \text { days) }\end{array}$ & $5.56(8.63)$ & $0-30$ \\
\hline $\begin{array}{l}\text { Alcohol drinks per drinking day (past } \\
30 \text { days) }\end{array}$ & $4.07(3.67)$ & $<1-14$ \\
\hline
\end{tabular}

Abbreviations: DSM-IV, Diagnostic and Statistical Manual of Mental Disorders, 4th Edition; MA, methamphetamine.

for MA, measured by the MAUQ, as compared with placebo; see Figure 1. Follow-up comparisons suggested that, although there was a significant increase in self-reported craving during the MA cue compared with the control cue in the placebo condition $(\mathrm{F}(1,30)=14.47, p<0.001)$, there was no significant effect of MA cues on craving during the NTX condition $(\mathrm{F}(1,32)=1.19, p=0.28)$.

Cardiovascular response. Elevations in heart rate and diastolic blood pressure in repsonse to the MA cues were blunted in the NTX conditon. Specifically, although the medication $\times$ trial effects were not statistically significant $(\mathrm{F}(1,28)=2.43, \quad p=0.13 ; \quad$ and $\quad \mathrm{F}(1,28)=2.66, \quad p=0.11$, 


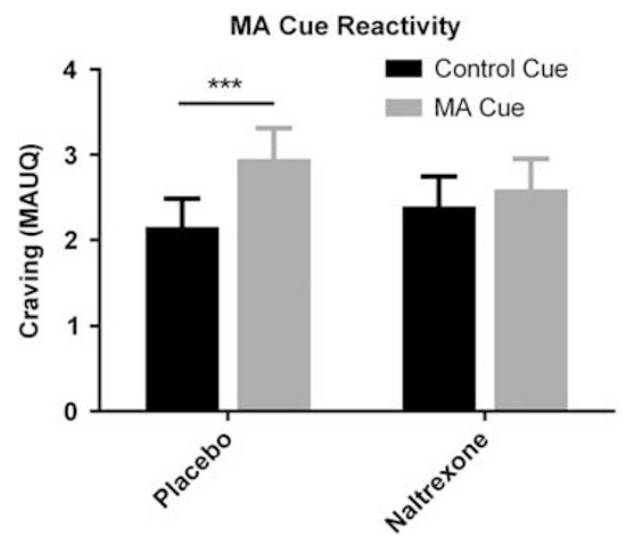

Figure I Craving scores (methamphetamine urge questionnaire $(M A \cup Q))$, presented with standard errors, following control and methamphetamine (MA) cue exposure during both placebo and naltrexone (NTX) conditions. Analyses revealed a significant medication $\times$ trial effect, such that NTX attenuated cue-induced craving for MA as compared with placebo. Asterisks represent planned comparisons; $* * * * 0<0.001$

respectively), planned comparisons indicated that there were significant increases in heart rate $(\mathrm{F}(1,29)=7.58, p<0.01)$ and diastolic blood pressure $(\mathrm{F}(1,29)=11.49, p<0.01)$, during the MA cue compared with control cue exposure, in the placebo condition, yet these effects were not significant in the NTX condition $(\mathrm{F}(1,32)=0.43, p=0.52$ and $\mathrm{F}(1,32)=0.15, \quad p=0.70, \quad$ respectively; Supplementary Figure 1). Systolic blood pressure increased during presentation of the MA cue vs the control cue, $(\mathrm{F}(1,28)=29.98$, $p<0.001)$ in both medication conditions, and the medication $\times$ trial effect for systolic blood pressure was not significant $(\mathrm{F}(1,28)=1.61, p=0.22)$. Together, these results suggest that NTX attenuated cue-induced craving for MA and attenuated the MA cue-provoked increases in heart rate and diastolic blood pressure during the NTX condition.

\section{MA Administration}

Subjective effects. Administration of MA resulted in immediate increases in the subjective effects of 'feel drug effects' 'like drug effects,' 'good drug effects,' 'drug high,' 'would like more drug,' 'crave drug,' 'stimulated' and 'would like drug access' immediately following MA administration (ie, baseline vs $5 \mathrm{~min}$ post MA infusion: $p$-values <0.01). Complete results for the effects of NTX on subjective effects of MA over the course of the MA challenge, each measured by individual items of DEQ, are presented in Table 2. Significant main effects of medication were observed in terms of 'crave drug,' 'stimulated,' and 'would like drug access' ( $p$-values $<0.05)$, such that NTX was associated with blunted increases (from baseline) on these constructs as compared with placebo (Figure 2). Furthermore, significant medication $\times$ trial interactions were observed with respect to 'feel drug effects,' and 'drug high,' although post hoc tests revealed no time points where the simple effect of medication was significant ( $p$-values $\geqslant 0.11$; Figure 3 ). Significant medication $\times$ trial interactions were also observed on 'anxious' and 'bad drug effects,' such that placebo was associated with increased anxiety from MA administration, particularly during later time points following MA infusion,
Naltrexone and response to methamphetamine

LA Ray et al

Table 2 Results of ANOVAs Testing the Effects of Medication, Trial (ie, time following MA administration), and Medication $\times$ Trial Effects on Subjective Responses to MA

\begin{tabular}{|c|c|c|c|c|c|c|}
\hline \multirow[t]{2}{*}{ Variable } & \multicolumn{2}{|c|}{ Medication } & \multicolumn{2}{|c|}{ Trial } & \multicolumn{2}{|c|}{$\begin{array}{c}\text { Medication } \\
\times \text { trial }\end{array}$} \\
\hline & $\mathbf{F}$ & $\boldsymbol{p}$ & $\mathbf{F}$ & $p$ & $\mathbf{F}$ & $p$ \\
\hline Crave drug & 5.63 & 0.025 & 4.12 & $<0.001$ & 0.41 & 0.90 \\
\hline Stimulated & 5.23 & 0.030 & 19.44 & $<0.0001$ & I. I & 0.36 \\
\hline Would like drug access & 5.48 & 0.026 & 7.78 & $<0.0001$ & 0.92 & 0.49 \\
\hline Feel drug effects & 0.33 & 0.57 & 39.48 & $<0.0001$ & 2.79 & 0.009 \\
\hline Bad drug effects & 2.69 & 0.11 & 0.72 & 0.65 & 2.68 & 0.011 \\
\hline Drug high & 0.28 & 0.60 & 34. I I & $<0.0001$ & 2.45 & 0.020 \\
\hline Anxious & 2.97 & 0.10 & 1.22 & 0.29 & 3.32 & 0.002 \\
\hline Like drug effects & 0.98 & 0.33 & I I.88 & $<0.0001$ & 0.46 & 0.86 \\
\hline Good drug effects & 0.11 & 0.74 & 28.08 & $<0.0001$ & 0.75 & 0.63 \\
\hline Would like more drug & 0.82 & 0.37 & 8.74 & $<0.0001$ & 0.87 & 0.53 \\
\hline Depressed & 1.4 & 0.25 & 3.05 & 0.005 & 0.2 & 0.99 \\
\hline
\end{tabular}

Abbreviations: ANOVA, analysis of variance; MA, methamphetamine.

Note: significant values of the effect of medication (ie, main effect or the medication $\times$ trial effect) are presented in bold type. Medication degrees of freedom $=1,29$. Trial and medication $\times$ trial degrees of freedom $=7,203$.

and NTX was associated with increased 'bad drug effects' during earlier time points following MA infusion (Figure 3).

Cardiovascular response. As expected, MA administration produced robust increases in heart rate $(\mathrm{F}(8,224)=$ 40.98, $p<0.0001)$, systolic blood pressure $(\mathrm{F}(8,224)=28.93$, $p<0.0001)$, and diastolic blood pressure $(\mathrm{F}(8,224)=6.05$, $p<0.0001)$. However, thee was no significant effect of medication on cardiovascular response to MA during the challenge, indexed by either a main effect of medication or a medication $\times$ trial interaction for any cardiovascular parameter $(p$-values $\geqslant 0.10)$.

\section{Adverse Events}

NTX and MA were generally well tolerated and there were no serious AEs during the study nor dropouts related to medication tolerability. A series of Fisher's exact tests, a nonparametric test appropriate for small cell sizes (Fisher, 1922), were conducted comparing the medicaiton $v s$ placebo on each of the 24 items from the SAFTEE administered on day 4 of each admission (prior to MA administraiton). The only AE that differed significantly between medication conditons was increased desire for sex, which was reported with higher frequency on the placebo $v s$ NTX conditions (5/30 on placebo $v s$ 2/30 on NTX; Fisher's exact $p=0.02$ ). In addition, we examined medication effects on nausea, which is NTX's most common side effect (O'Malley et al, 2000), and found that 3/30 participants reported nausea on NTX as compared with $1 / 30$ on placebo; this difference was not statistically significant (Fisher's exact $p=0.10$ ) and suggests that AEs are unlikely to account for the medication effects reported above. 
DEQ "Would like more drug"

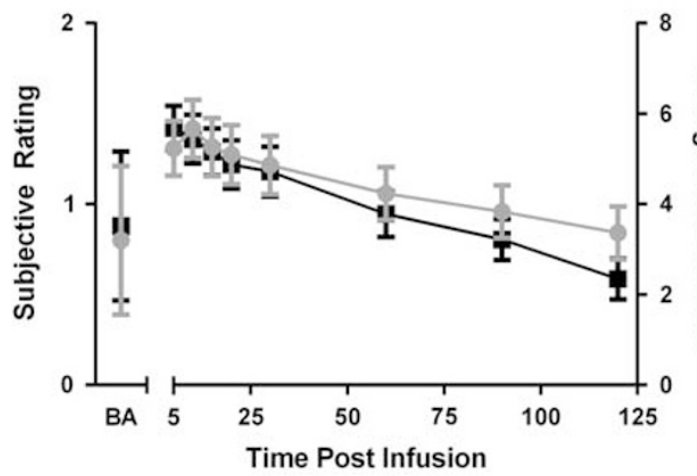

DEQ "Crave drug"

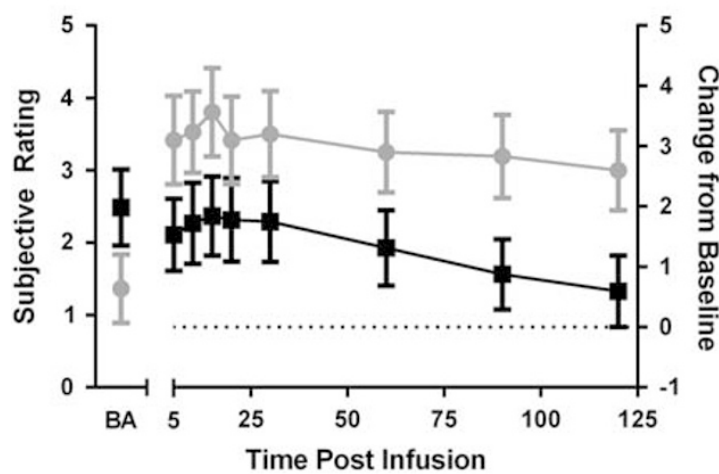

Placebo
DEQ "Stimulated"

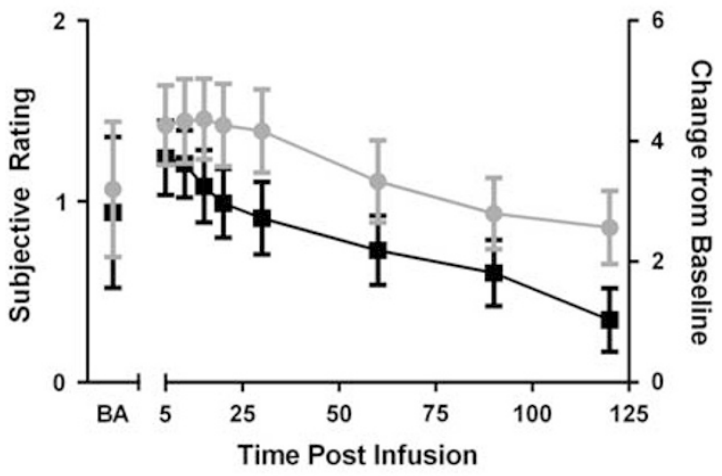

DEQ "Would like drug access"

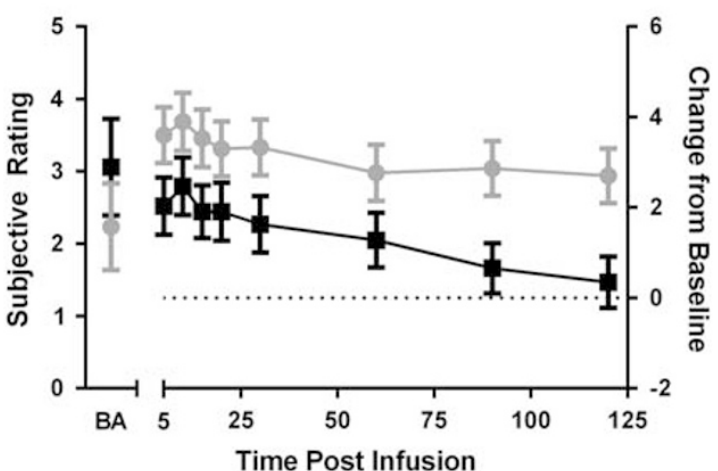

Naltrexone

Figure 2 Subjective response scores (drug effects questionnaire (DEQ)), presented with standard errors, at baseline (BA) and change from baseline at $5,10,15,20,30,60,90$, and 120 min following methamphetamine (MA) administration, during both placebo and naltrexone (NTX) conditions. Analyses revealed a significant main effect of medication, such that NTX attenuated ratings of 'stimulated,' 'crave drug,' and 'would like drug access,' as compared with placebo.

\section{Sex Differences}

Owing to the within-subjects design, all reported effects were robust to controlling for sex. Despite the small number of female participants $(n=8)$, exploratory analyses of sex effects were conducted and some differences were observed. Specifically, females reported lower 'like drug effects' overall $(\mathrm{F}(1,28)=4.51, p<0.05)$, and reported a larger difference between NTX and placebo in terms of drug 'feel drug effects' (medication $\times$ sex: $\mathrm{F}(1,28)=4.87, p<0.05$ ). Three-way medication $\times$ trial $\times$ sex interactions were observed in terms of 'would like more drug,' 'depressed,' and 'would like drug access' $(\mathrm{F}(7,196)=2.32,2.44$, and 3.25, respectively, $p$-values $<0.05)$. These effects were such that females demonstrated a larger NTX effect than males in terms of 'would like more drug' and 'would like drug access,' particularly at later time points following MA administration (eg, >60 min post infusion; see Supplementary Figure 2).

\section{DISCUSSION}

In this human behavioral pharmacology study, an interesting pattern of results emerged whereby NTX blunted cueinduced craving for MA and attenuated some of the subjective effects of MA during a controlled MA administration and as compared with placebo. Specifically, participants reported lower subjective ratings of 'stimulated,' 'crave drug,' and 'would like drug access,' on the NTX condition, as compared with placebo. Interestinlgy, participants reported lower ratings of 'anxiousness' in the NTX condition, as compared with placebo, and these differences were more prominent at later time points following MA administration. Medication also moderated ratings of 'bad drug effects' following MA administration, such that ratings of 'bad drug effects' were higher on NTX than placebo at earlier time points following MA infusion. NTX did not significantly alter peak MA effects; however, although peak drug responses are important factors in stimulant abuse (Hart et al, 2008), the modulation of broader acute subjective effects, such as those observed in this study, represent equally important targets for pharmacological intervention. As would be predicted, there were elevations in heart rate and blood pressure in response to the MA cues and to the MA administration. Notably, NTX attenuated the cue-induced elevation of heart rate and diastolic blood pressure.

On balance, these results are consistent with previous work on amphetamines (Jayaram-Lindstrom et al, 2008b; Jayaram-Lindstrom et al, 2004) and cocaine (Comer et al, 2013), suggesting that NTX may have anti-craving properties and may alter subjective respones to stimulants. This is the first study of NTX and MA and combines several strengths, such as a sample comprised of individuals with clinically 
DEQ "Feel drug effects"

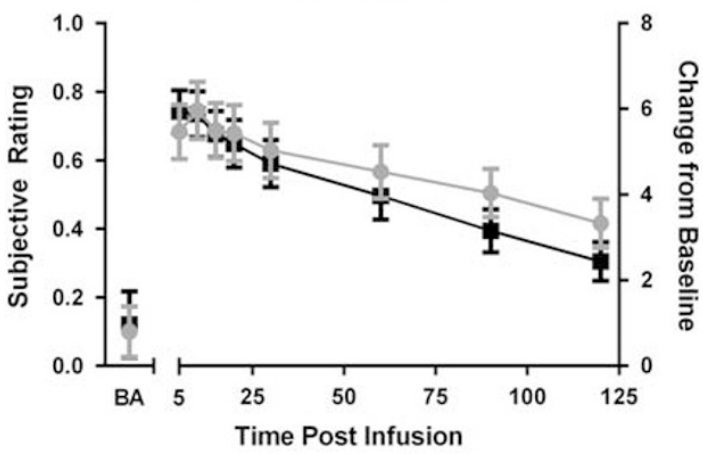

DEQ "Anxious"

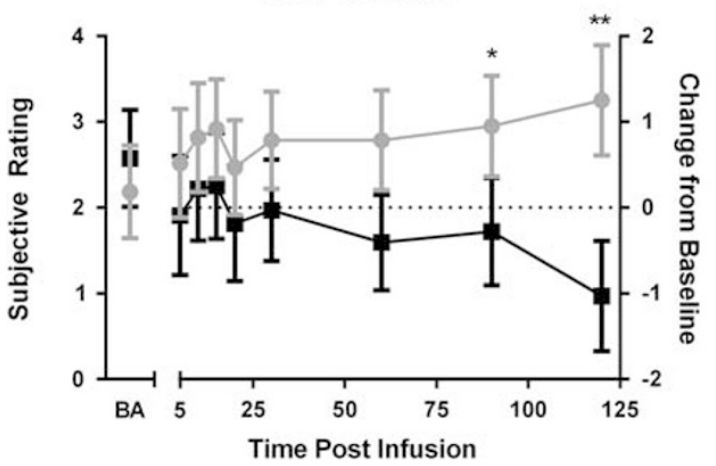

DEQ "Drug high"

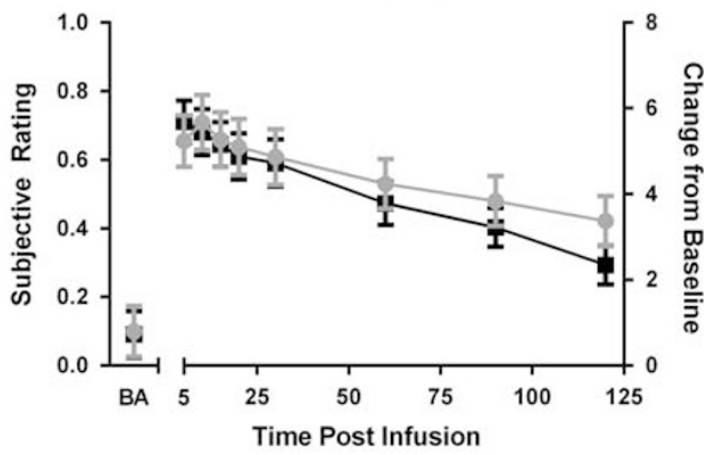

DEQ "Bad drug effects"

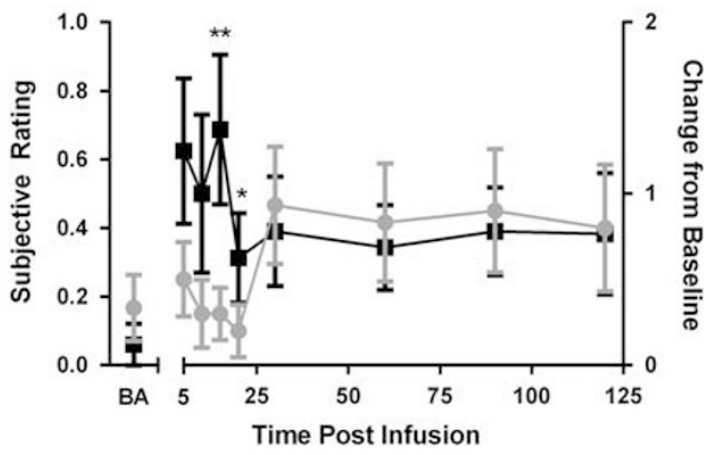

- Placebo

Naltrexone

Figure 3 Subjective response scores (drug effects questionnaire (DEQ)), presented with standard errors, at baseline (BA) and change from baseline at 5, I0, 15, 20, 30, 60, 90, and 120 min following methamphetamine (MA) administration, during both placebo and naltrexone (NTX) conditions. Analyses revealed significant medication $\times$ trial effects on 'feel drug effects' and 'drug high' as compared with placebo (although no post hoc tests were significant). Further, NTX was associated with lower 'anxious' ratings from MA administration at later time points and greater 'bad drug effects' during early time points. Asterisks refer to statistically significant post hoc tests, which were conducted at each time point in trial; $* p<0.05$, $* * 0<0.0$ I.

significant MA problems, a controlled behavioral pharmacology design in the context of inpatient hospital admissions, a crossover design allowing subjects to serve as their own controls, excellent overall retention, and rigorous laboratory paradigms with putative clinical significance such as cueexposure and MA administration. Study limitations include the single dose of NTX, the lack of a placebo MA administration, and the non-treatment-seeking nature of the sample. Injectable NTX was also considered but rejected in favor of the oral formulation, given the non-treatmentseeking nature of the sample and the need for a timely washout period allowing for the crossover design. In addition, the present findings are unlikely to be due to NTX-induced side effects for two reasons: first, no significant differences between NTX and placebo were observed on any subjective effects at baseline when side effects were assessed. Second, the analyses are baseline corrected, thus reducing the likelihood that these findings are reflective of, for example, NTX-related nausea.

Taken together, this study provides support for the notion that NTX may be useful for the treatment of MA dependence, thus extending upon positive trials for stimulant dependence (Jayaram-Lindstrom et al, 2008a) and polydrug dependence (Tiihonen et al, 2012). Although no clinical trials to date have tested NTX for the treatment of MA dependence, with the exception of a small combination study (Grant et al, 2010), the present work suggests that such trials may be warranted. In fact, a clinical trial of long-acting, injectable NTX for MA was recently completed (NCT00984360; results are not yet available) and another is currently under way (NCT01449565).

The potential efficacy of NTX, an opioid antagonist with greatest affinity for the $\mu$-opioid receptor and to a lesser but meaningful extent $\kappa$ - and $\delta$-opioid receptors (Lee et al, 1988; Weerts et al, 2008), for the treatment of drug use disorders beyond alcoholism and opioid dependence may lie on a common mechanism of drug effects involving the activation of the endogenous opioid system (Herz, 1997; Kreek, 1996). Acute oral amphetamine administration has been shown to induce endogenous opioid release in many brain regions frequently implicated in addiction, including the basal ganglia, frontal cortex areas, thalamus, and striatum (Colasanti et al, 2012; Mick et al, 2014). Further, elevated frontal/temporal cortical $\mu$-opioid receptor binding has been observed in cocaine dependence, the degree of which was shown to positively correlate with self-reported cocaine craving (Gorelick et al, 2005), and relate to relapse following treatment (Ghitza et al, 2010; Gorelick et al, 2008). NTX has been shown to block ethanol-induced $\beta$-endorphin and subsequent dopamine release in the nucleus accumbens and provide a blockade of ethanol-induced $\beta$-endorphin inhibition of GABAergic inhibitory interneurons in the ventral tegmental area (Johnson, 2008; Zalewska-Kaszubska et al, 2006). The decrease in amphetamine-induced dopamine 
levels in the nucleus accumbens following blockade of the $\mu$ opioid receptor by naltrindole (a selective $\delta$-opioid receptor antagonist) and $\beta$-funaltrexamine (an irreversible $\mu$-opioid receptor antagonist) provides support for a similar NTX mechanism in the case of stimulants (Schad et al, 1996). The present study supports the role of the opioidergic system in the incentive salience of MA cues as well as the modulation of the subjective effects of MA during IV administration. Thus, there may be a role for NTX in the treatment of MA use disorders, particularly in light of novel long-acting delivery systems that can enhance medication compliance. This may be particularly relevant for drug-using populations and is consistent with the hypothesis that low medication adherence may account, at least in part, for the modest effect size of NTX in clinical trials (Swift et al, 2011). The combination of NTX with other pharmacotherapies may be valuable, as we have recently found in our work combining varenicline and NTX for smokers who drink heavily (Ray et al, 2014a, b). Finally, although exploratory in nature, analyses of sex effects suggested added benefit of NTX for female participants on a few measures of subjective responses. The present sample was comprised primarily of males (75\%), hence future analyses in gender-balanced samples are warranted.

In conclusion, this behavioral pharmacology study is the first to test the effects of NTX on cue-induced craving and subjective responses to MA among individuals with MA abuse and dependence. These findings suggest that NTX is superior to placebo in attenuating cue-induced craving for MA, as well as several dimensions of MA-induced subjective effects (eg, 'stimulated' and 'crave drug') measured during controlled MA administration. To the extent to which laboratory measures of cue-induced craving and subjective responses to MA may be predictive of clinical response to this pharmacotherapy among treatment seekers, these results suggest that clinical trials of NTX for MA dependence may be warranted. Although there is enthusiasm for behavioral pharmacology approaches to screen for medications for addiction (Litten et al, 2012; Mason and Higley, 2013; Ray et $a l, 2010)$, a required step consists of demonstrating that laboratory-based measures of cue-induced craving and subjective effects do in fact predict treatment response. Notably, recent studies have demonstrated that cue-induced craving predicted relapse among alcohol- (Seo et al, 2013) and heroin- (Fatseas et al, 2011) dependent patients, respectively. Although the present study does not effectively link biobehavioral responses in the laboratory to clinical outcomes, it suggests that NTX reduces cue-induced craving for MA as well as craving and stimulation ratings during MA administration. Given the significance of craving as a determinant of drug intake and possibly as a predictor of relapse, the effects of NTX observed in this study hold promise for clinical studies of this medication for MA dependence.

\section{ACKNOWLEDGMENTS}

We would like to acknowledge the assistance of Taylor Rohrbaugh, Anna Sheng, Brooke Rowland, and Christopher Stumpf for data collection and data management for this project. We wish to thank the staff at the UCLA/Westwood Clinical and Translational Research Center.

\section{FUNDING AND DISCLOSURE}

This research was supported by a grant from the National Institute on Drug Abuse (DA029831) to LAR. Support for this study was also provided by a grant from the UCLA Clinical and Translational Science Institute, grants UL1RR033176 and UL1TR000124. KEC, NRM, and DR were supported by the UCLA Training Program in Translational Neuroscience of Drug Abuse (T32 DA024635). SB was supported by a training grant from the National Institutes of Alcohol Abuse and Alcoholism (F31 AA022569) and KEC was supported by a training grant from the National Institute on Drug Abuse (F31 DA035604). LR has received study medication from Pfizer and MediciNova. $\mathrm{KH}$ has received compensation from Gilead for serving on an advisory board and has received study medication from Pfizer and MediciNova.

\section{REFERENCES}

Anggadiredja K, Sakimura K, Hiranita T, Yamamoto T (2004). Naltrexone attenuates cue- but not drug-induced methamphetamine seeking: a possible mechanism for the dissociation of primary and secondary reward. Brain Res 1021: 272-276.

Anton RF, O'Malley SS, Ciraulo DA, Cisler RA, Couper D, Donovan DM et al (2006). Combined pharmacotherapies and behavioral interventions for alcohol dependence: the COMBINE study: a randomized controlled trial. JAMA 295: 2003-2017.

Bohn MJ, Krahn DD, Staehler BA (1995). Development and initial validation of a measure of drinking urges in abstinent alcoholics. Alcohol Clin Exp Res 19: 600-606.

Brensilver M, Heinzerling KG, Shoptaw S (2013). Pharmacotherapy of amphetamine-type stimulant dependence: an update. Drug Alcohol Rev 32: 449-460.

Chiu CT, Ma T, Ho IK (2005). Attenuation of methamphetamineinduced behavioral sensitization in mice by systemic administration of naltrexone. Brain Res Bull 67: 100-109.

Chiu CT, Ma T, Ho IK (2006). Methamphetamine-induced behavioral sensitization in mice: alterations in mu-opioid receptor. J Biomed Sci 13: 797-811.

Colasanti A, Searle GE, Long CJ, Hill SP, Reiley RR, Quelch D et al (2012). Endogenous opioid release in the human brain reward system induced by acute amphetamine administration. Biol Psychiatry 72: 371-377.

Comer SD, Mogali S, Saccone PA, Askalsky P, Martinez D, Walker EA et al (2013). Effects of acute oral naltrexone on the subjective and physiological effects of oral D-amphetamine and smoked cocaine in cocaine abusers. Neuropsychopharmacology 38: $2427-2438$.

Cook CE, Jeffcoat AR, Hill JM, Pugh DE, Patetta PK, Sadler BM et al (1993). Pharmacokinetics of methamphetamine selfadministered to human subjects by smoking S-(+)-methamphetamine hydrochloride. Drug Metab Dispos 21: 717-723.

Cornish JW, Metzger D, Woody GE, Wilson D, McLellan AT, Vandergrift B et al (1997). Naltrexone pharmacotherapy for opioid dependent federal probationers. J Subst Abuse Treat 14: 529-534.

Elkashef A, Vocci F, Hanson G, White J, Wickes W, Tiihonen J (2008). Pharmacotherapy of methamphetamine addiction: an update. Subst Abus 29: 31-49.

Fatseas M, Denis C, Massida Z, Verger M, Franques-Reneric P, Auriacombe M (2011). Cue-induced reactivity, cortisol response 
and substance use outcome in treated heroin dependent individuals. Biol Psychiatry 70: 720-727.

First MB (2005). Structured Clinical Interview for DSM-IV-TR Axis I Disorders: Patient Edition. USA: Biometrics Research Department, Columbia University: New York, NY, USA.

Fisher RA (1922). On the interpretation of $\mathrm{x}(2)$ from contingency tables, and the calculation of P. J R Stat Soc 85: 87-94.

Ford CP, Mark GP, Williams JT (2006). Properties and opioid inhibition of mesolimbic dopamine neurons vary according to target location. J Neurosci 26: 2788-2797.

Ghitza UE, Preston KL, Epstein DH, Kuwabara H, Endres CJ, Bencherif B et al (2010). Brain mu-opioid receptor binding predicts treatment outcome in cocaine-abusing outpatients. Biol Psychiatry 68: 697-703.

Gorelick DA, Kim YK, Bencherif B, Boyd SJ, Nelson R, Copersino M et al (2005). Imaging brain mu-opioid receptors in abstinent cocaine users: time course and relation to cocaine craving. Biol Psychiatry 57: 1573-1582.

Gorelick DA, Kim YK, Bencherif B, Boyd SJ, Nelson R, Copersino ML et al (2008). Brain mu-opioid receptor binding: relationship to relapse to cocaine use after monitored abstinence. Psychopharmacology (Berl) 200: 475-486.

Grant JE, Odlaug BL, Kim SW (2010). A double-blind, placebo-controlled study of $\mathrm{N}$-acetyl cysteine plus naltrexone for methamphetamine dependence. Eur Neuropsychopharmacol 20: $823-828$

Haggkvist J, Lindholm S, Franck J (2008). The opioid receptor antagonist naltrexone attenuates reinstatement of amphetamine drug-seeking in the rat. Behav Brain Res 197: 219-224.

Haggkvist J, Lindholm S, Franck J (2009). The opioid receptor antagonist naltrexone attenuates reinstatement of amphetamine drug-seeking in the rat. Behav Brain Res 197: 219-224.

Hart CL, Gunderson EW, Perez A, Kirkpatrick MG, Thurmond A, Comer SD et al (2008). Acute physiological and behavioral effects of intranasal methamphetamine in humans. Neuropsychopharmacology 33: 1847-1855.

Herz A (1997). Endogenous opioid systems and alcohol addiction. Psychopharmacology (Berl) 129: 99-111.

Itzhak Y, Ali SF (2002). Behavioral consequences of methamphetamine-induced neurotoxicity in mice: Relevance to the psychopathology of methamphetamine addiction. Ann N Y Acad Sci 965: 127-135.

Jayaram-Lindstrom N, Hammarberg A, Beck O, Franck J (2008a). Naltrexone for the treatment of amphetamine dependence: a randomized, placebo-controlled trial. Am J Psychiatry 165: $1442-1448$.

Jayaram-Lindstrom N, Konstenius M, Eksborg S, Beck O, Hammarberg A, Franck J (2008b). Naltrexone attenuates the subjective effects of amphetamine in patients with amphetamine dependence. Neuropsychopharmacology 33: 1856-1863.

Jayaram-Lindstrom N, Wennberg P, Hurd YL, Franck J (2004). Effects of naltrexone on the subjective response to amphetamine in healthy volunteers. J Clin Psychopharmacol 24: 665-669.

Jimenez-Gomez C, Winger G, Dean RL, Deaver DR, Woods JH (2011). Naltrexone decreases D-amphetamine and ethanol self-administration in rhesus monkeys. Behav Pharmacol 22: 87-90.

Johnson BA (2008). Update on neuropharmacological treatments for alcoholism: Scientific basis and clinical findings. Biochem Pharmacol 75: 34-56.

Kreek MJ (1996). Opiates, opioids and addiction. Mol Psychiatry 1: 232-254.

Lee MC, Wagner HN Jr, Tanada S, Frost JJ, Bice AN, Dannals RF (1988). Duration of occupancy of opiate receptors by naltrexone. $J$ Nucl Med 29: 1207-1211.

Levine J, Schooler NR (1986). SAFTEE: a technique for the systematic assessment of side effects in clinical trials. Psychopharmacol Bull 22: 343-381.
Litten RZ, Egli M, Heilig M, Cui C, Fertig JB, Ryan ML et al (2012). Medications development to treat alcohol dependence: a vision for the next decade. Addict Biol 17: 513-527.

MacKillop J (2006). Factor structure of the alcohol urge questionnaire under neutral conditions and during a cue-elicited urge state. Alcohol Clin Exp Res 30: 1315-1321.

Mason BJ, Higley AE (2013). A translational approach to novel medication development for protracted abstinence. Curr Top Behav Neurosci 13: 647-670.

Mick I, Myers J, Stokes PR, Erritzoe D, Colasanti A, Bowden-Jones $\mathrm{H}$ et al (2014). Amphetamine induced endogenous opioid release in the human brain detected with [11C]carfentanil PET: replication in an independent cohort. Int J Neuropsychopharmacol 17: 2069-2074.

Monti PM, Binkoff JA, Abrams DB, Zwick WR, Nirenberg TD, Liepman MR (1987). Reactivity of alcoholics and nonalcoholics to drinking cues. J Abnorm Psychol 96: 122-126.

Morean ME, de Wit H, King AC, Sofuoglu M, Rueger SY, O'Malley SS (2013). The drug effects questionnaire: psychometric support across three drug types. Psychopharmacology (Berl) 227: 177-192.

Newton TF, Reid MS, De La Garza R, Mahoney JJ, Abad A, Condos $\mathrm{R}$ et al (2008). Evaluation of subjective effects of aripiprazole and methamphetamine in methamphetaminedependent volunteers. Int $J$ Neuropsychopharmacol 11: 1037-1045.

Newton TF, Roache JD, De La Garza R 2nd, Fong T, Wallace CL, $\mathrm{Li} \mathrm{SH}$ et al (2006). Bupropion reduces methamphetamineinduced subjective effects and cue-induced craving. Neuropsychopharmacology 31: 1537-1544.

O'Malley SS, Jaffe AJ, Chang G, Schottenfeld RS, Meyer RE, Rounsaville B (1992). Naltrexone and coping skills therapy for alcohol dependence. A controlled study. Arch Gen Psychiatry 49: 881-887.

O’Malley SS, Krishnan-Sarin S, Farren C, O'Connor PG (2000). Naltrexone-induced nausea in patients treated for alcohol dependence: clinical predictors and evidence for opioidmediated effects. J Clin Psychopharmacol 20: 69-76.

Ray LA, Courtney KE, Ghahremani DG, Miotto K, Brody A, London ED (2014a). Varenicline, low dose naltrexone, and their combination for heavy-drinking smokers: human laboratory findings. Psychopharmacology (Berl) 231: 3843-3853.

Ray LA, Courtney KE, Ghahremani DG, Miotto K, Brody A, London ED (2014b). Varenicline, naltrexone, and their combination for heavy-drinking smokers: preliminary neuroimaging findings. Am J Drug Alcohol Abuse 41: 35-44.

Ray LA, Hutchison KE, Tartter M (2010). Application of human laboratory models to pharmacotherapy development for alcohol dependence. Curr Pharm Des 16: 2149-2158.

Schad CA, Justice JB Jr., Holtzman SG (1996). Differential effects of delta- and mu-opioid receptor antagonists on the amphetamineinduced increase in extracellular dopamine in striatum and nucleus accumbens. J Neurochem 67: 2292-2299.

Seo D, Lacadie CM, Tuit K, Hong KI, Constable RT, Sinha R (2013). Disrupted ventromedial prefrontal function, alcohol craving, and subsequent relapse risk. JAMA Psychiatry 70: 727-739.

Sobell LC, Sobell MB, Leo GI, Cancilla A (1988). Reliability of a timeline method: assessing normal drinkers' reports of recent drinking and a comparative evaluation across several populations. Br J Addict 83: 393-402.

Substance Abuse and Mental Health Services Administration (SAMHSA) (2013). Results from the 2012 National Survey on Drug Use and Health: Summary of National Findings. NSDUH Series H-46, HHS Publication No. (SMA) 13-4795. Substance Abuse and Mental Health Services Administration: Rockville, MD, USA.

Suzuki T, Mori T, Tsuji M, Misawa M, Nagase H (1997). The role of delta-opioid receptors in the discriminative stimulus properties of a low dose of methamphetamine. Eur J Pharmacol 331: 1-8. 
Swift R, Oslin DW, Alexander M, Forman R (2011). Adherence monitoring in naltrexone pharmacotherapy trials: a systematic review. J Stud Alcohol Drugs 72: 1012-1018.

Tiihonen J, Krupitsky E, Verbitskaya E, Blokhina E, Mamontova O, Fohr J et al (2012). Naltrexone implant for the treatment of polydrug dependence: a randomized controlled trial. Am J Psychiatry 169: 531-536.

Tolliver BK, McRae-Clark AL, Saladin M, Price KL, Simpson AN, DeSantis SM et al (2010). Determinants of cue-elicited craving and physiologic reactivity in methamphetaminedependent subjects in the laboratory. Am J Drug Alcohol Abuse 36: 106-113.
Volpicelli JR, Alterman AI, Hayashida M, O’Brien CP (1992). Naltrexone in the treatment of alcohol dependence. Arch Gen Psychiatry 49: 876-880.

Weerts EM, Kim YK, Wand GS, Dannals RF, Lee JS, Frost JJ et al (2008). Differences in delta- and mu-opioid receptor blockade measured by positron emission tomography in naltrexone-treated recently abstinent alcohol-dependent subjects. Neuropsychopharmacology 33: 653-665.

Zalewska-Kaszubska J, Gorska D, Dyr W, Czarnecka E (2006). Effect of acute administration of ethanol on beta-endorphin plasma level in ethanol preferring and non-preferring rats chronically treated with naltrexone. Pharmacol Biochem Behav 85: 155-159.

Supplementary Information accompanies the paper on the Neuropsychopharmacology website (http://www.nature.com/npp) 